\title{
Complex development of a digital platform of the agricultural economy
}

\author{
Elmira Amirova ${ }^{1, *}$, Ilnur Safiullin ${ }^{1}$, Amina Sakhbieva $^{2}$ and Timur Aygumov ${ }^{3}$ \\ ${ }^{1}$ Kazan State Agrarian University, Kazan, 420015, Russia \\ ${ }^{2}$ University of management "TISBI", Kazan, 420012, Russia \\ ${ }^{3}$ Dagestan State Technical University, Makhachkala, 367000, Russia
}

\begin{abstract}
This paper describes the key points in the development of a digital platform for the agrarian economy of Russia. The main problems of transition of the Russian economy to a digital format of work, development, expansion of digital literacy, ways of solving the problems of digitalization of agricultural production are revealed. The creation of complex digital models of production processes in agriculture will increase the productivity of the business of agricultural producers. This requires generally valid agricultural production management systems with hundreds of parameters and analysis of big data, which includes the formation and algorithmization of management: equipment, devices, things, processes, money supply. Each platform is built on the management of the processes of crop production, livestock production, logistics of supply and sale. The basis of the digital platform which is being created as a knowledge platform that reflects the availability of professional staff in creating the necessary programs and providing farms with new IT opportunities to increase productivity. Thus, according to our research, improvement of digital infrastructure can be attributed to the main directions of development of digital technologies in the agricultural sector; updating the human resources of citizens by reducing the digital divide; orientation towards the use of domestic scientific and technical developments; development of domestic technologies correlated with scientific developments. A comprehensive scientific and technical program should also include a training system for the development and functioning of digital agriculture, and this requires the modernization of the entire educational process in agricultural educational institutions.
\end{abstract}

\section{Introduction}

The term "automation of production" means computer automation with the aim of reducing or eliminating human labor and transferring only management functions to it.

Due to the mechanization and automation of the agroindustrial complex, labor productivity can be increased. New technologies are also helping to increase the volume and quality of agricultural products. These processes are directly related to the use of agro-industrial technologies in this industry, as well as to the improvement of planning and management $[1,2]$. Agricultural automation is the ability to effectively and efficiently manage the agroindustrial complex as a whole.

The main areas of digitalization of the economy and individual industries include the following structural elements: legislation [3]; creation and optimization of information infrastructure; creation of a single information space [4]; development of a training program for qualified personnel [5]; ensuring information security; digital government; creation of effective digital technologies.
The complexity of the mass digitalization of the agroindustrial complex lies in the fact that the transformations affect the most complex objects of property law from a legal point of view - land and natural resources, which are subject to several types of law at the same time [6].

Currently, the Digital Agriculture program, created by the Ministry of Agriculture, regulates the transformation in the agro-industrial complex. This project is to allocate funds for optimizing the information component in agriculture, attracting public resources, extra-budgetary resources and financing from agribusiness in the period from 2019 to 2024. At the same time, less money is spent on these processes than in other industries. The main distinguishing feature of the digitalization of agriculture is the uneven use of digital technologies in farms of different categories. At the beginning of 2019, in Russia, precision farming technologies are used only in $3 \%$ of farms. In the developed countries of Europe, this figure is more than $80 \%$ [7].

With the digitalization of the agro-industrial complex, it is planned to develop several complex projects to increase productivity: "Smart farm"; "Smart Field"; "Smart greenhouse"; "Smart Garden". Agriculture today

\footnotetext{
*Corresponding author: elmira_amirova@mail.ru
} 
is gradually approaching the start of a second green revolution. Experts believe that if we use technologies of precision farming and the "Internet of Things", the yield will increase dramatically to such an extent that the use of herbicides will be stopped, as a result of which the ecological purity of food will increase $[8,9,10]$.

The introduction of local digital services can be significantly changed as a result of the digitalization of agriculture, as a result of that agricultural organizations will reduce their costs for equipment, communications, premises, the use of unskilled labor, as well as the introduction of precision technologies, etc. Maximum digitalization and automation of all processes in agriculture has become the main task of the largest agroindustrial and engineering companies in the world. In particular, to accelerate the economic growth of agricultural enterprises, ensure a stable result in the introduction of innovations and increase their competitiveness on a local and global scale, it will be possible due to the huge amount of information collected and advanced data management systems [11, 12, 13].

Equipping the agro-industrial complex with digital technologies has both positive and negative sides. Positive aspects: lower prices, higher labor productivity, increase of the number of highly qualified personnel, etc. The disadvantages of this process include: the risk of unemployment and, as a consequence, the emergence of prerequisites for the stratification of society and the growth of social tension; crowding out low-skilled specialists by more educated and highly qualified personnel.

All digital technologies for agriculture and related industries can be combined into groups: 1) big data is a whole range of different tools, approaches and methods of working with information that allow solving several global problems; 2) blockchain technologies: for monitoring and maintaining databases of transactions with land resources in agriculture [14]; 3) digitization of production (robotics, "smart" technologies, agricultural machinery with artificial intelligence, well-equipped satellites and drones, point irrigation systems, etc.) [2].

The main directions of state policy in the sphere of agriculture are determined on the basis of the Decree of the Government of the Russian Federation of December 19, 2014 No. 1421 "On amendments to the State program for the development of agriculture and regulation of markets for agricultural products, raw materials and food for 2013-2020", and also in the subprogram "Ensuring the implementation of the State Program of the Federal Scientific and Technical Program for the Development of Agriculture for 2017-2025" documents ensure the full development of all sectors and subsectors and activities of agro-industrial enterprises.

In the process of creating and operating of the state program "Digitalization of Agriculture", the interest of scientists and researchers in digital technologies, their advantages, improvements is growing, many startups appear, the goal of which is to create perspective effective agricultural technologies $[15,16,17]$.

This is due to the active exchange of intelligent technologies in the world. Evidence of this phenomenon was presented as additional benefits at the world presentation of advanced technologies in Hanover from 25 November to 7 November 2017.

Let's consider several recommendations for digitalization in the agro-industrial complex. For example, in 2017 the Kuban agricultural holding launched a separate project "Fertilizers together with Agronout". This project has contributed to higher yields. Also since 2009, WEED-IT has been automating the weed detection system. Due to this technology, only weeds are sprayed, which saves up to $90 \%$ of the cost of chemicals [18].

Agrosila's digital livestock technologies (Tatarstan) are mainly concerned with feeding, veterinary medicine, genetics and improving the comfort of animal breeding. In 2019, the company launched an analytical project for the production of milk and dairy products. The program allows you to analyze and control key indicators in real time, receive timely notifications of deviations and reliable forecasts $[19,20]$.

Based on the foregoing, the following conclusion can be made: the transition from manual labor to digital labor will allow agriculture not only to increase production efficiency, reduce production costs, but also increase the country's competitiveness. Unfortunately, there are many reasons why this process is slowing down: the population does not accept innovations, it is difficult for people to introduce new technologies, to use "best practices" [21]. One of the main reasons for the slowdown in agricultural automation is also the lack of government motivation, i.e. various subsidies.

However, it should be noted that the technological equipment of the agro-industrial complex has a positive effect on both the state and entrepreneurs, since this is a kind of monopsony (the state is the only buyer). As various companies develop new technologies, they improve existing ones, which are mainly of interest to the state, i.e. it is the main, and in some cases even the only consumer.

\section{Methods}

In order to clarify the essence of concept of the integrated development of the digital platform of the agrarian economy and modern achievements in the studied area of knowledge, a large number of literary sources on the development of digital agricultural production were analyzed using methods of critical analysis of literary sources, general scientific methods of the system approach, analogy and design, abstract-logical and statistical and economic methods.

\section{Results and Discussion}

The agro-industrial complex is one of the most important components of the economy of any state in the modern world. The agricultural sector is an indispensable basis for ensuring the country's economic security, and above all its food security. The innovative development of agriculture in modern conditions has reached a sufficiently high level and provides a stable growth rate of agricultural production, but there are still significant reserves for the growth of the studied industry. 
In this regard, the discovery of the latest reserves for the growth of agro-industrial production will give the impulse to development of the entire agro-industrial complex of Russia. At the moment, one of such impulses is the introduction of the latest achievements of digitalization into the structural production elements of the agricultural industry.

Currently, control over the implementation of digital technologies in the structure of the agro-industrial complex is carried out by monitoring the implementation of the Digital Agriculture program, which was created directly under the leadership of the Ministry of Agriculture. Within the framework of the aforementioned program, first of all, it is planned to allocate funds for the improvement and development of digitalization in the agricultural segment with the expected future attraction of a decent level of investment from extra-budgetary funds under targeted programs of state structures. It should be emphasized that when implementing the process of transition of the agro-industrial complex to the active operation of digital technologies, the level of costs becomes significantly lower in comparison with other industries. A characteristic feature of the digitalization process is the uneven use of technologies by farms of different categories and types.

During the course of the procedure for implementation of digital technologies into the agro-industrial sector, it is assumed that various directions for improving the production criterion are being developed comprehensively. Among them are: "Smart Garden", "Smart Field", "Smart Greenhouse", "Smart Farm", as well as "Digital Land Use".

The "Smart Garden" direction is a highly intelligent system for the preparation, control and execution of all kinds of technological operations for growing horticultural products using automated machines and unmanned units. It implies the development of a technical system of an intellectual nature, which automatically makes a variety of management decisions and their implementation by technical means, as well as the analysis of information on the state of the agrobiocenosis of the garden.

The "Smart Field" direction is the basis for ensuring sustainable growth in agricultural production using digital technologies for collecting, using and processing data on the state of soils and the environment as a whole.

The "Smart greenhouse" direction is an agricultural object isolated from external processes, which receives crop production in an automatic mode, which greatly diminishes human participation. It represents the development of an integrated technology based on the use of the Internet of Things, which will significantly reduce costs for many complexes with a minimum level of costs for technical equipment or design innovative facilities.

The Smart Farm direction is an autonomous structure that is fully automated. Its true purpose lies in the breeding of agricultural livestock in an automatic mode with the absence of mandatory human participation. It involves the production of a complex of automated units for agricultural crops, the creation of various kinds of competitive technologies, as well as the invention of the latest systems for the protection of animals.
The direction of "Digital land use" is a progressive system that automatically analyzes, collects and updates information on the state of land and soil resources, develops various recommendations for the uniform distribution of agricultural crops, the placement of crop rotations, crop cultivation technologies, the most accurate assessment of land plots, control systems of land use and landscape farming, their impact on the ecological environment, as well as agricultural. The development of these areas will have a significant impact on the efficiency of the entire structure of agriculture and its productivity.

The development of a complex platform for digital technologies in the agro-industrial segment involves the following form of transformation:

1) introduction of the artificial intelligence components, as well as the beginning of the widespread use of automated labor, will improve the quality of products and reduce production costs. According to detailed studies of various specialists in the field of economics, the percentage of costs of agricultural enterprises that can be reduced due to digital technologies is approximately thirty percent;

2) beginning of the use of large-scale information systems that support various solutions in the agroindustrial environment. The activities of these systems are aimed at converting geobotanical data into digital form using satellites and various other high-tech systems and forms. According to the final results of all detailed and accurate assessments, a manufacturer of agricultural products is forced to solve over 25 different issues during the season under conditions of total uncertainty. A large number of such solutions have the potential to become objects of the digitalization process in the future.

3 ) main basis of all system data is built on the basis of a detailed analysis of a large amount of information. Such an analysis provides an opportunity to gain access to the assimilation of information from new samples and the construction of various connections that are necessary for the qualitative summing up of all analytical components to a single result.

To seriously involve agricultural objects into the digitalization process, the state is required to immediately start creating the required infrastructure, closely monitor the implementation of the popularization of developing areas and actively improve the legislative framework. The last criterion is of great importance for reducing the level of possible risks of various contradictions between the legal framework and the real interactions of regulators with business.

The development of digital technologies by the agroindustrial complex will open up the following opportunities: providing all the necessary information to producers of agricultural products; distribution in an even order of a large number of upcoming works in the field; reducing the level of risks in the production of agricultural products; significant improvement in the quality and quantity of yields in the agricultural sector; underestimation of the costs that are allocated for the producing of products based on the efficient use of resources, scientific approaches; reduction of costs when performing transactions of a purchase and sale transaction [22]. 
Summing up, we can confidently assert that the digitalization of agriculture is an integrated and progressive approach, which is a different kind of activities, starting from the collection and analysis of initial configurations, up to the education and professional training of highly qualified specialists of the innovative generation of the future. The transition to the activities using digital technologies means an increase in the competitiveness of manufactured products, an increase in the level of profitability in many structures of the agroindustrial complex and the creation of numerous conditions for the country's food security.

\section{Conclusion}

Through the digital transformation of agriculture, it is possible to solve the following tasks: increasing labor productivity; integration of information resources; provision of government services and portals for agricultural producers; stimulating domestic development and providing access to various digital open platforms; introduction of online trading platforms and systems for the promotion of agricultural products (raw materials, semi-finished products, processed products); creation of a platform for the processes of forming proposals for adjusting regulatory legal acts and regulatory and technical requirements for the transition to the digital economy.

The digital platform of the agrarian economy of Russia has much to strive for. Therefore, for the development of one of the important sectors of the economy, specifically the agricultural sector, it is necessary to comprehensively approach the situation, to make a plan and think carefully about further decisions on the development of a digital platform for the agricultural economy of Russia.

\section{References}

1. E. Bulatova, E. Amirova, Financial Impact of Digital Technologies as a Promising Element of Import Substitution, International Journal of Financial Research, 11(5), 392-398 (2020)

2. A. Subaeva, M. Nizamutdinov, L. Mavlieva, Changes of the agricultural staff potential in the transition to digital agriculture, $\mathrm{BIO}$ Web of Conferences, 00178 (2020)

3. A. Subaeva, M. Nizamutdinov, L. Mavlieva, M. Kalimullin, Labor productivity in digital agriculture, BIO Web of Conferences, 00226 (2020)

4. A. Sharnin, O. Frolova, G. Klychova, N. Nigmatullina, A. Iskhakov, Formation and development of clusters in the Russian regional agro-industrial complex, E3S Web of Conferences, 91, 06005 (2019)

5. O. Bakhareva, Strategic Planning of Infrastructure Development: BIM and Intelligent Building, Journal of Advanced Research in Law and Economics, 10(8 (46)), 2262-2270 (2019)
6. A. Zakirova, G. Klychova, O. Doroshina, I. Safiullin, R. Nurieva, Z. Zalilova, Improvement of the procedure for assessing the personnel of the agricultural organization, E3S Web of Conferences, 110(11), 02073 (2019)

7. N. Kashapov, M. Nafikov, M. Gazetdinov, M. Nafikova, A. Nigmatzyanov, Innovative production technology ethanol from sweet sorghum, IOP Conf. Ser. Mater. Sci. and Engineer., 134012012 (2016)

8. A. Mentsiev, Z. Gerikhanov, A. Isaev, Automation and IoT for controlling and analysing the growth of crops in agriculture, Journal of Physics: Conference Series, 1399, 1-6 (2019)

9. E. Amirova, O. Kirillova, M. Kuznetsov, Sh. Gazetdinov, Internet of things as a digital tool for the development of agricultural economy, BIO Web of Conferences, 00050 (2020)

10. A. Zolkin, A. Losev, D. Gridina, T. Aygumov, Research of problems of computer networks expert systems, IOP Conference Series: Materials Science and Engineering, 1047(1), 0121065 (2021)

11. D. Bunkovsky, Entrepreneurial risk management tools, Manag. Issues, 1(37), 65-76 (2019)

12. I. Sokolova, O. Leskina, O. Orlovtseva, E. Gubanova, T. Kanikhin, Application of artificial intelligence capabilities for practical needs of participants in economic processes, in: Proc. of the 33th Int. Busin. Inform. Manag. Associat. Conf., IBIMA 2019: Education Excellence and Innovation Management through Vision, pp. 8592-8602 (2019)

13. V. Zhuravlyov, N. Varkova, S. Aliukov, T. Khudyakova, Strategic Aspects of Ensuring Sustainable Development of Gold Enterprises of the Russian Federation, Sustainability, 10, 4410 (2018)

14. G.D. Krupina et al., Analysis of the digitalization efficiency in agricultural complex in the Republic of Tatarstan, BIO Web of Conferences, 17, 00230 (2020)

15. E. Ermakova, Yu. F. Korotkov, M. Kuznetsov, N. Nikolaev, Cleaning contaminated water by gravity flotation, Chemical and Petroleum Engineering, 46(1-2), 40-44 (2010)

16. O. Rostova, S. Shirokova, N. Sokolitsyna, Management of project for automation of investment control at industrial enterprise, IOP Conf. Ser. Mater. Sci. and Engineer., 497(1), 012017 (2019)

17. V. Zhuravlyov, T. Khudyakova, N. Varkova, S. Aliukov, S. Shmidt, Improving the Strategic Management of Investment Activities of Industrial Enterprises as a Factor for Sustainable Development in a Crisis, Sustainability, 11, 6667 (2019)

18. V. Timiryanova, K. Grishin, D. Krasnoselskaya, Spatial Patterns of Production-DistributionConsumption Cycle: The Specifics of Developing Russia, Economies, 8(4), 87 (2020)

19. M. Zharova, S. Shirokova, O. Rostova, Management of pilot IT projects in the preparation of energy resources, E3S Web of Conf., 110, 02033 (2019) 
20. V. Zhakhov, V. Krivoshlykov, N. Slavova et al., State Influence on the Development of Digital Economy of Rational Nature Use in Agricultural Sector of the Region's Economy, in: Proc. of XVIII Int. Sci. and Pract. Conf. Modern Trends in Agricultural Production in the World Economy, pp. 182-189 (2020)
21. S. Kosnikov, T. Aygumov, F. Khamkhoeva, D. Krasnoselskaya, Regional specificities of small business development in Russia, Amazonia Investiga, 9(28), 519-527 (2020)

22. V. Fattakhov, M. Nizamutdinov, V. Oreshnikov, Analysing and modelling of trends in the development of the territorial settlement system in Russia, Economy of Region, 15(2), 436-450 (2019) 